\title{
Estudio previo al registro en el Atlas del Patrimonio Inmaterial
}

Al sur de la provincia de Cádiz se sitúa la comarca del Campo de Gibraltar, una de las más reconocidas y consolidadas de Andalucía. Aunque se constatan asentamientos de mayor antigüedad, podemos atender a tres periodos históricos en la configuración de la comarca. En época romana se consolidan núcleos que articulan la economía del "círculo del estrecho", manteniendo relaciones con otras ciudades romanas de la región. Durante el Califato de Córdoba, componen junto con Barbate una kora califal; el territorio se articuló en la Edad Media en torno a tres ciudades: Al-Yazirat Al-Hadra (Algeciras), AlYazirat Al-Tarif (Tarifa) y Ghebel Tarik (Gibraltar). Por último, la pérdida de Gibraltar en el siglo XVIII implicó la toma de los territorios anejos (posteriormente La Linea de la Concepción) y la reafirmación de la comarca frente a la "colonia del Peñón".

Los municipios se dividen entre la franja costera y el interior, de manera que en el medio físico encontramos sierras de poca altura en el eje central, playas en los flancos y una importante reserva acuifera, con ríos procedentes de las sierras del Aljibe y en la serranía de Ronda. Los ríos Guadiaro, Guadarranque, Hozgarganta y Palmones tienen varios embalses que abastecen de agua a la población. En cuanto a espacios naturales protegidos, destacan el parque natural de los Alcornocales, del que participan seis de los siete municipios de la comarca, y el parque natural del Estrecho de Gibraltar, de ámbito marino-terrestre; por otro lado, encontramos los parajes naturales de la playa de Los Lances en Tarifa, del estuario del Río Guadiaro en San Roque y de las marismas del río Palmones entre Los Barrios y Algeciras.

Las actividades económicas han estado históricamente alejadas de la agricultura debido a las caracteristicas del medio, centradas prácticamente en la ganadería, la pesca y en industrias derivadas de ésta, o en el comercio marítimo, donde aún destaca el puerto de Algeciras como referente a nivel nacional e internacional. A partir de la segunda mitad del siglo $X X$, las industrias petroquimicas se convierten en el gran brazo de la economía campogibraltareña. Hasta esos años, destacaron las industrias de transformación y conservación de productos pesqueros (sobre todo factorías de salazón), con trayectoria desde la conquista romana y que, a partir de la década de 1970, entraron en una importante crisis.

Por su parte, el turismo, sin ser de gran importancia, posee tres focos de interés (deportes acuáticos, turismo de playa y el paso desde o hacia Gibraltar), eclipsando en gran medida los atractivos históricoculturales de la comarca.

En el registro del patrimonio cultural inmaterial de la comarca del Campo de Gibraltar dentro del proyecto Atlas del Patrimonio Inmaterial de Andalucía se priorizarán aquellos referentes con un importante valor simbólico y social o de sostenibilidad medioambiental, poniendo de manifiesto las caracteristicas propias de los municipios que conforman esta comarca. La riqueza en manifestaciones de carácter inmaterial y las peculiaridades del entorno histórico y actual ofrecen a esta zona un interés particular. Destacaremos, a continuación, algunos de los elementos a considerar para el posterior registro según las categorías contempladas en el Atlas del Patrimonio Inmaterial.

\section{Rituales festivos}

Las numerosas fiestas de la demarcación se concentran en los meses de mayo a agosto, dejando un pequeño número de ellas para el primer trimestre del año. La actividad pesquera es fundamental para la comprensión de la importancia del período estival, donde tipologias festivas como las fiestas de la Virgen del Carmen cobran gran importancia. Del mismo modo, son reseñables las fiestas de San Juan, que suelen celebrarse con grandes hogueras en las playas. El gran número de veladas y ferias tiene lugar también en estos meses.

Entre los ciclos festivos destacan los Carnavales, la Semana Santa (con peculiaridades propias en cada municipio), romerías como las de la Virgen de la Luz de Tarifa y, por ser expresión del poblamiento concentrado-disperso de la zona, las de los pequeños asentamientos de Facinas o Tahivilla.

\section{Oficios y saberes}

En general, los oficios y saberes relacionados con la pesca (como tejer las redes) carecen de interés en la actualidad. El copo si se sigue utilizando como un arte de pesca relacionado con la zona, así como el palangre sigue presente en pequeñas embarcaciones. En relación con la pesca, la alfarería se desarrolló en época romana para el transporte marítimo de los productos, aunque hoy día su producción se reduce a algunos núcleos como La Línea o Tarifa.

En lo que respecta a los productos pesqueros, es de destacar los conocimientos asociados a la preparación de platos como el pulpo a la brasa y el espeto, realizado este último por los espeteros, que conocen la técnica y generalmente asociado al ámbito masculino.

Los bruscos cambios de viento que se producen en el Estrecho influyen en multitud de actividades cotidianas, por lo que existe un importante conocimiento y manejo sobre las influencias de cada viento en tareas y actividades socioeconómicas (por supuesto, la pesca), pero también en actividades de la vida cotidiana.

En Los Barrios, destaca el descorche en el parque natural de Los Alcornocales, explotado históricamente y hasta nuestros dias. El corcho proporciona unos grandes beneficios a los propietarios de las explotaciones de alcornocal, con el inconveniente de que precisa una serie de años para la renovación del alcornoque entre cada saca. Se realiza siempre durante los meses estivales.

\section{Modos de expresión significativos}

Algunos modos de expresión están ligados a rituales festivos; las procesiones marítimo-terrestres de la

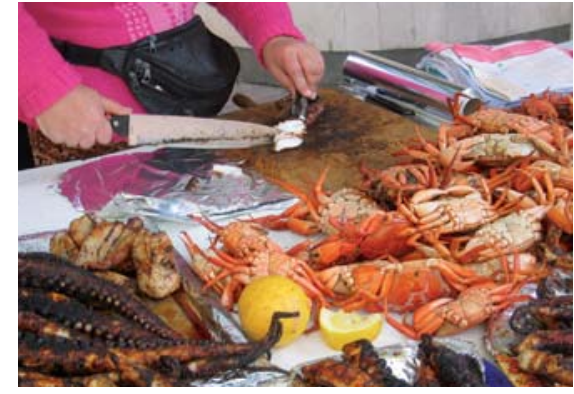

Puesto ambulante de pulpo a la brasa en la feria de La Línea de la Concepción (2005).

Foło: Anjhara Gómez Aragón

Virgen del Carmen son numerosas en los municipios costeros, asi como las hogueras de San Juan, donde la tradición consiste en mojarse con el agua del mar; se dice que el viento que sople la noche de San Juan será el que prevalezca durante el verano.

Diversos factores han desencadenado la presencia de un gran número de leyendas populares: las relaciones y contactos históricos con musulmanes e ingleses, la influencia de los vientos o el contrabandismo aparecen entre las historias más comunes. Dentro del patrimonio oral, hay que señalar las caracteristicas especificas del habla linense consecuencia de su cercanía y relación con Gibraltar, con apropiación y transculturación de vocabulario procedente del inglés.

En Tarifa se mantiene el chacarrá, baile y cante propios de varias localidades andaluzas, emparentado con el fandango desde el punto de vista musical. El cante se acompaña con guitarra, palillos y pandereta, entre otros instrumentos de percusión.

\section{Alimentación/cocinas}

La gastronomía campogibraltareña es muy variada y cuenta con influencias de diversa indole. El pescado constituye un elemento básico, sobre todo en los núcleos costeros. Mantienen importancia la producción de salazones como el volaor. Otros platos que destacan por la peculiaridad de su preparación son los espetos de sardina y el pulpo a la brasa, que podemos encontrar en puestos itinerantes, sobre todo en momentos festivos. La jibia en amarillo, los garbanzos con jibia o bacalao, o las conchas finas son otras muestras de la cocina marinera de la comarca y del aprovechamiento de los productos pesqueros.

En reposteria destacan los dulces de tradición morisca, sobre todo en Tarifa. En Jimena, los roscos de vino y el piñonate. En La Línea, la repostería ha tenido influencia gibraltareña, encontrando flanes o puddings y los llamados panquequis (del inglés pan-cake).

Anjhara Gómez Aragón, Grupo de investigación GEISA, Universidad de Sevilla 